\title{
FORMULATION AND EVALUATION OF COLON TARGETED TABLETS OF MESALAZINE
}

\author{
*Sharma Madhu ${ }^{1}$, Joshi Baibhav ${ }^{2}$, Bansal Monika ${ }^{1}$, Goswami Manish ${ }^{1}$ \\ ${ }^{1}$ Department of Pharmaceutics, Akal College of Pharmacy, Mastuana Sahib-148001, Punjab \\ ${ }^{2}$ Department of Pharmaceutics, Rayat Institute of Pharmacy, Railmajra-144533, Punjab \\ *Corresponding Author's E mail: sharma.madhu545@gmail.com
}

Received 24 July 2012; Review Completed 03 Sep 2012; Accepted 03 Sep 2012, Available online 15 Sep 2012

\begin{abstract}
In the present investigation an attempt was made to formulate the time and $\mathrm{pH}$ dependent drug delivery system, reduce the frequency of dose administeration, to prevent ulcerative colitis by developing sustained delayed release tablets of Mesalazine using combination of Eudragit S-100 and L-100 as enteric coating. The core tablets of Mesalazine were prepared using wet granulation containing a superdisintegrant. The aim of present study is to develop colon specific drug delivery of Mesalazine sustained release matrix tablets for ulcerative colitis using HPMC K-4M and HPMC K-15M as a semisynthetic polymer. Effect of polymer concentration and superdisintegrant level was also investigated. The matrix tablets of Mesalazine are subjected to an in-vitro drug release study using simulated gastric fluid $(0.1 \mathrm{~N} \mathrm{HCl})$ for 2 hours, simulated intestinal fluid (pH 7.4$)$ for 3 hours and simulated colonic fluid $(\mathrm{pH}$ 6.8) for 7 hours as dissolution fluid. The study showed that, lag time prior to drug release was highly affected by the coating. Colon drug delivery is advantageous in treatment of colonic disease and oral delivery of drugs that are unstable and susceptible to enzymatic degradation in upper GI tract. The disintegration data obtained from tablets demonstrated that disintegration data rate of studied tablets is dependent on: (i) The polymer used to coat the tablets (ii) $\mathrm{pH}$ of disintegration media. Results also demonstrated that combination of Eudragit S-100 and L-100 can be successfully used to coat tablets for colon targeted delivery of drug.

Keywords: Time and $\mathrm{pH}$ dependent drug delivery system, ulcerative colitis, mesalazine, wet granulation.
\end{abstract}

\section{INTRODUCTION}

Over the past several years there has been a dramatic increase in bowel diseases. Approximately one third of patients with mucosal ulcerative colitis undergo operative treatment. ${ }^{1}$ In recent years, colon targeted delivery systems have been the focus point of formulation laboratories because the colon is considered as a suitable site for the delivery of both conventional and labile molecules, and it is also a site for some specific diseases, such as, ulcerative colitis, crohn's disease, bowel cancer, some infections, and constipation, which require local delivery of the $\operatorname{drug}(\mathrm{s}){ }^{2}$ Colonic drug delivery may be achieved by either oral or rectal administration. Rectal dosage forms (enemas and suppositories), are not always much effective due to high variability in the distribution of drug administered by this route. $^{3}$ The major obstacle with the delivery of drugs by oral route to the colon is the absorption and degradation of the drug in the upper part of gastrointestinal tract (GIT) which must be overcome for successful colonic drug delivery. ${ }^{4}$

Various approaches have been used for oral delivery of $\operatorname{drug}(\mathrm{s})$ to the colon which includes time dependent delivery, $\mathrm{pH}$ - dependent systems and bacteria- dependent delivery. The $\mathrm{pH}$ dependent systems exploit the generally accepted view that $\mathrm{pH}$ of human gastrointestinal (GI) tract increases progressively from the stomach $(\mathrm{pH} \mathrm{2-3)}$, small intestine $(\mathrm{pH}$ 6.5-7) to the colon (7.0-8.0). Taking advantage of the highest $\mathrm{pH}$ value of the colon content, the dosage form containing the active drug in the core is coated with $\mathrm{pH}$ dependent material which dissolves at the $\mathrm{pH}$ of colon. But recent studies using sensitive and reliable equipments contradict the traditional view and provide

evidence of a fall in $\mathrm{pH}$ at the GI region between ileum and colon. ${ }^{5,6}$ Apparently, colon has a lower $\mathrm{pH}$ value (6.5) than the small intestine (7.0-7.8), and the jejunal region of some individuals has a higher $\mathrm{pH}$ range (6.1-7.2) than the small intestine or colon of other individuals. ${ }^{2}$

Ulcerative colitis is the anti inflammatory disease of the colonic mucosa which is restricted to large intestine and is usually treated with salicylates or glucocorticoids. However, during periods of remission mesalamine is the drug of choice. In this case it is desirable to localize the release of mesalamine to the afflicted site in the colon. ${ }^{7-9}$ Thus, Mesalamine was used as a model drug in the present study. Mesalamine is an anti inflammatory drug, for oral adminsteration in the treatment of diseases of colon (ulcerative colitis, crohn's disease, carcinomas and infections) whereby high local concentration can be achieved while minimizing side effects that occur because of release of drugs in the upper GIT or unnecessary systemic absorption. ${ }^{10}$

\section{OBJECTIVES}

The objective of this study is to develop formulations using a combination of time and $\mathrm{pH}$ dependent system for delivering mesalamine to the colon and to sustain the release of the drug using various grades of HPMC (HPMC $\mathrm{K}-4 \mathrm{M}$ and HPMC $\mathrm{K}-15 \mathrm{M}$ ) so as to reduce the dosing frequency of the drug and to demonstrate its site specificity in the colon. Effect of polymer concentration and the superdisintegrant concentration was also investigated.

Methacrylic acid copolymers such as Eudragit S-100 and Eudragit L-100 have been commonly used as $\mathrm{pH}$ SSN: 2250-1177 CODEN (USA): JDDTAO 
dependent polymers for coating solid dosage forms (because of their solubility at $\mathrm{pH} 6.0$ or higher and 7.0 or higher respectively), none of them is suitable for use alone for coating of solid dosage forms that would start releasing the drug specifically at $\mathrm{pH} 6.4$ which is generally considered as the suitable $\mathrm{pH}$ for colon targeted drug delivery. ${ }^{11-13}$ A major drawback of Eudragit coated $\mathrm{pH}$ dependent formulation is premature release of drug in small intestine. ${ }^{14}$

\section{MATERIALS AND METHODS}

Mesalazine (5-amino salicylic acid) was obtained from Hi-media Pvt Ltd., Mumbai. HPMC K-4M and HPMC K$15 \mathrm{M}$ were obtained as free gift sample from Colorcon Asia Pvt. Ltd., Goa. Crosspovidone, Eudragit L-100 and S-100 were obtained from Yarrowchem products, Mumbai. Starch and magnesium stearate were obtained from S.d fine chem., Mumbai and Lactose was obtained from Qualikems fine chemicals Ltd, New Delhi. All reagents and solvents used were of analytical grade satisfying pharmacopoeial standards.

\section{1) ANALYTICAL METHOD VALIDATION}

\subsection{Linearity and Range ${ }^{15}$}

Aliquots of different concentration of Mesalazine were prepared upto highest concentration, till linearity was observed and absorbance was recorded at $302 \mathrm{~nm}$ for acidic media, $331.60 \mathrm{~nm}$ and $331.70 \mathrm{~nm}$ for phosphate buffer of $\mathrm{pH} 6.8$ and 7.4 respectively.

\subsection{Limit of Detection (LOD) ${ }^{15,16}$}

The LOD of Mesalazine was determined in placebo solution. It was based on the standard deviation of the blank. It was computed from the calibration graphs using the equation $3.3 \sigma / \mathrm{s}$ where $\sigma$ is the standard deviation of three blank determinations and $\mathrm{s}$ is the slope of calibration curve. The detection limit of an individual analytical procedure is the lowest amount of analyte in a sample which can be detected but not necessarily quantitated as an exact value.

\subsection{Limit of Quantitation ${ }^{15,16}$}

The quantitation limit is a parameter of quantitative assays for low levels of compounds in sample matrices, and is used particularly for the determination of impurities and/or degradation products. It was computed from the calibration graphs using the equation $10 \sigma / \mathrm{s}$, where $\sigma$ is the standard deviation of three blank determinations and $s$ is the slope of calibration curve.

\section{2) FOURIER TRANSFORM INFRARED SPECTROSCOPY (FTIR) STUDY}

The IR absorption spectrum of the pure drug was taken in the range of $4000-450 \mathrm{~cm}$ using $\mathrm{KBr}$ pellet method .The major peaks were reported for evaluation of purity. Observed peaks are similar to reported peaks of Mesalazine.

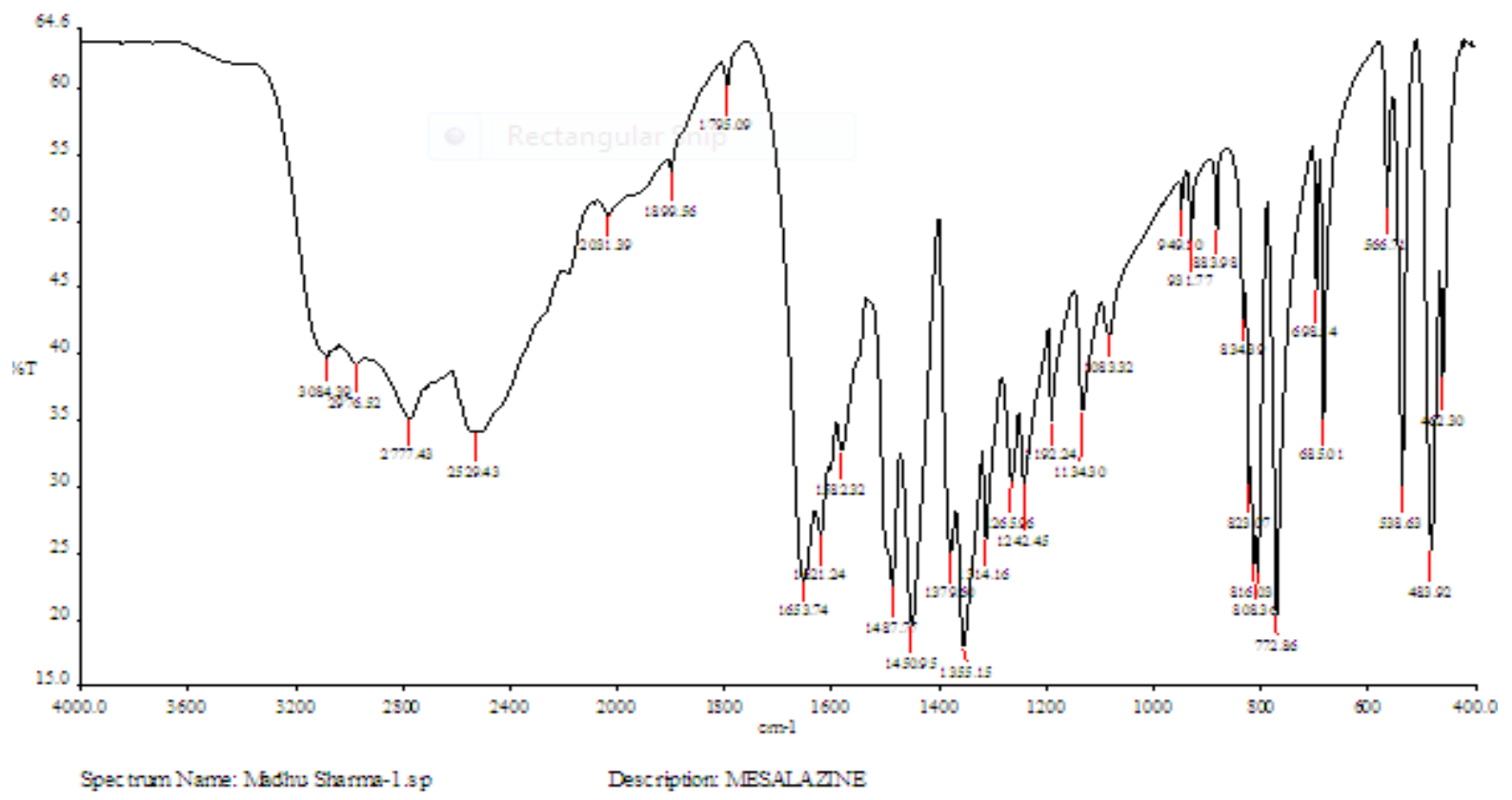

Figure 1: FTIR spectra of Mesalazine

Table 1: Interpretation of FTIR Spectra of Mesalazine:

\begin{tabular}{ccc}
\hline S.No & Functional Group & Peaks Observed \\
\hline 1) & C=C stretch of the aromatic group; & 1621.24 \\
2) & N-H bond scissoring & 2976.52 \\
3) & C-H stretch of the aromatic group & 1487.79 \\
4) & C-C stretching mode & $1582,1487,1450$ \\
5) & O-H deformation of the hydroxyl groups & 1194.90 \\
6) & C-O stretching mode & $1192.24-1265.96$ \\
7) & In plane bending mode & 685.01 \\
& C-H bond out of plane bending mode; Ring & \\
\hline
\end{tabular}




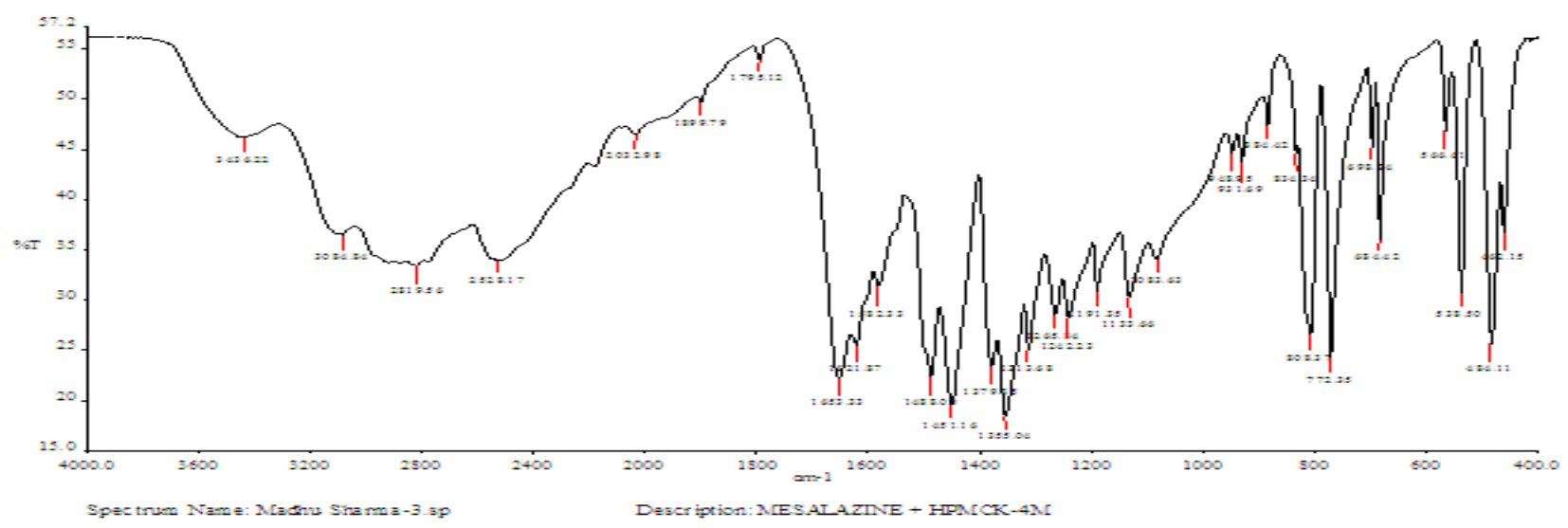

Figure 2: FTIR Spectra of Mesalazine + HPMC K-4M

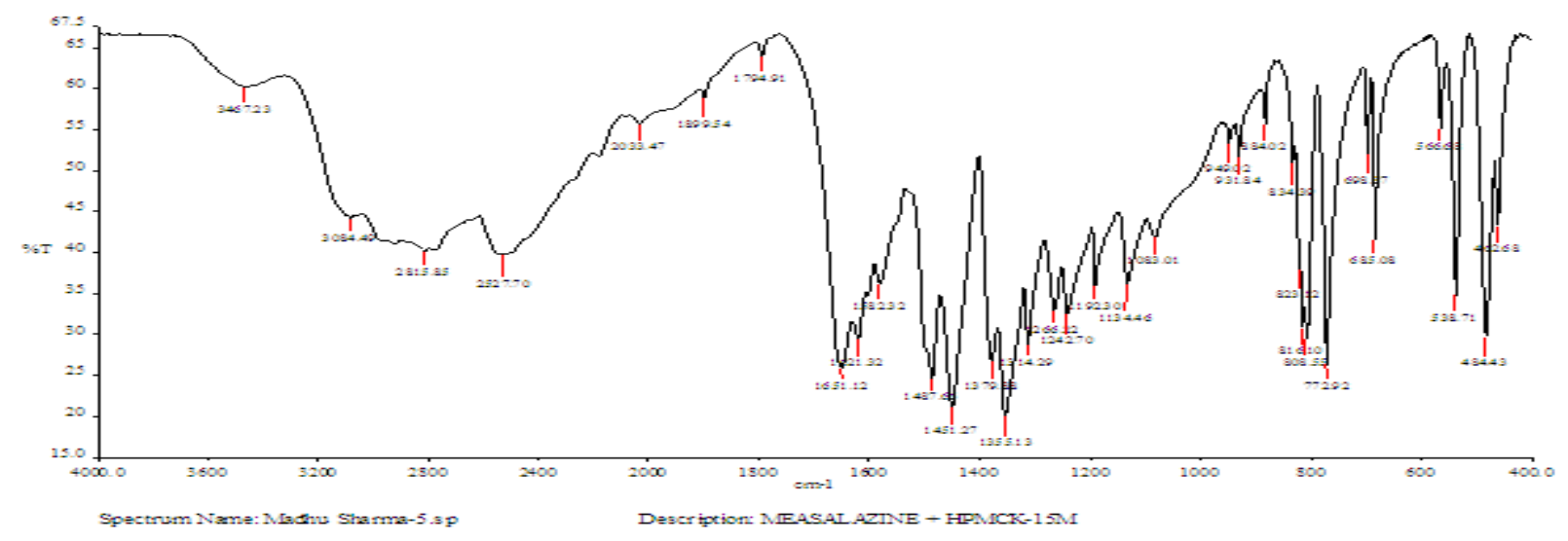

Figure 3: FTIR Spectra of Mesalazine + HPMC K-15M

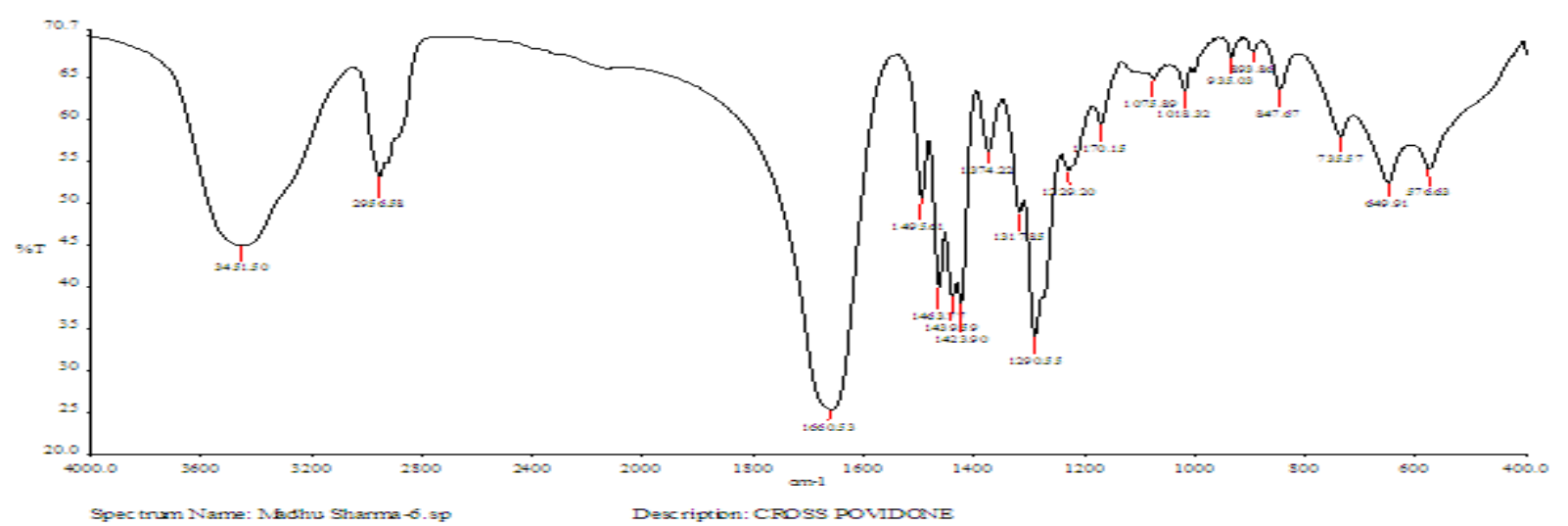

Figure 4: FTIR Spectra of Mesalazine + Crosspovidone

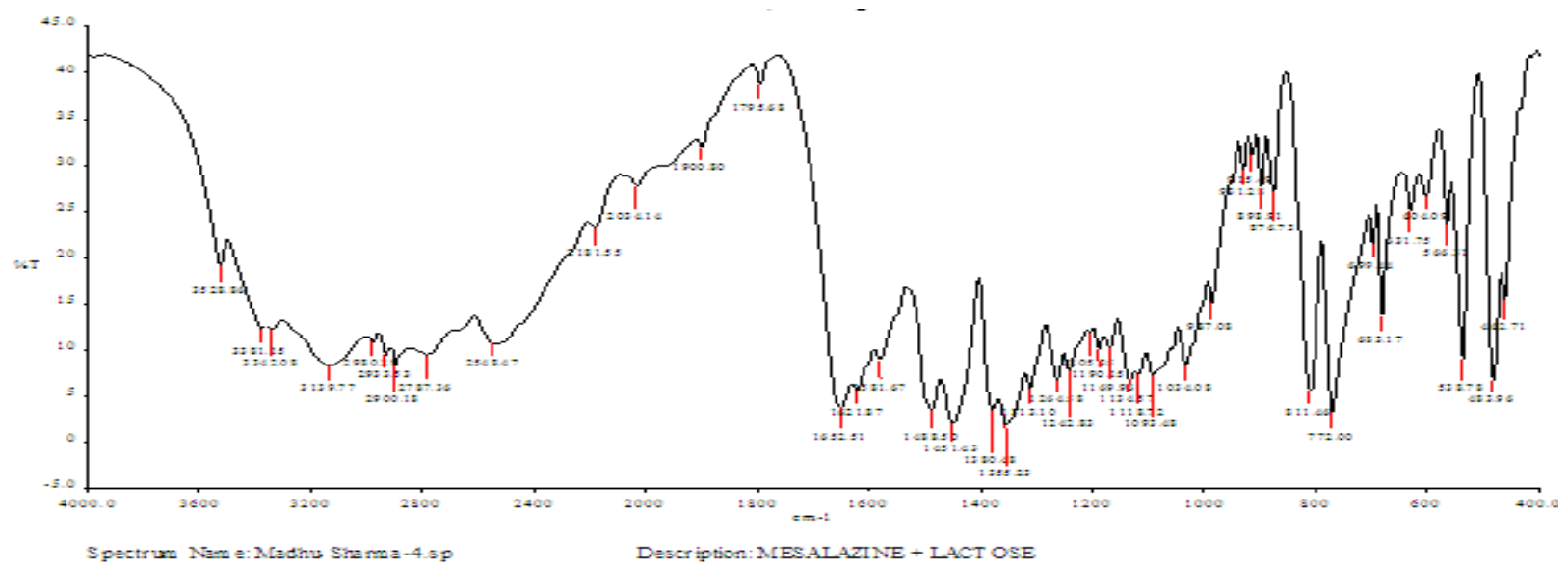

Figure 5: FTIR Spectra of Mesalazine + Lactose 


\section{3) PREPARATION OF CORE TABLETS}

All the ingredients were weighed separately. Mesalazine, lactose, crosspovidone and HPMC (K-4M, K-15M either alone or in combination) were passed through the $16 \#$ sieve and thoroughly mixed and then granulated using starch solution (1\% in iso propyl alcohol) as a binder. The granules so obtained were dried at $50-60{ }^{\circ} \mathrm{C}$ for $2 \mathrm{hr}$ in the oven. These granules were lubricated with flow promoters like magnesium stearate. The flow properties of the granules were determined. The lubricated granules were compressed into tablets (each $600 \mathrm{mg}$ ) using using $12 \mathrm{~mm}$ concave-faced punch of 10 station Rimek compression machine. Weight variation, hardness, friability, and disintegration test were performed for the core tablets.

Table 2: Composition of Different Core Tablets of Mesalazine

\begin{tabular}{ccccccccc}
\hline Ingredients & F1 & F2 & F3 & F4 & F5 & F6 & F7 & F8 \\
\hline Mesalazine & 400 & 400 & 400 & 400 & 400 & 400 & 400 & 400 \\
HPMC K4M & 120 & 120 & 110 & 110 & 10 & 10 & 60 & 60 \\
HPMC K 15M & - & - & 10 & 10 & 110 & 110 & 60 & 60 \\
Magnesium stearate & 2 & 2 & 2 & 2 & 2 & 2 & 2 & 2 \\
Starch (1\%) & q.s & q.s & q.s & q.s & q.s & q.s & q.s & q.s \\
Crosspovidone & 7.2 & 14.4 & 7.2 & 14.4 & 7.2 & 14.4 & 7.2 & 14.4 \\
& $(1.2 \%)$ & $(2.4 \%)$ & $(1.2 \%)$ & $(2.4 \%)$ & $(1.2 \%)$ & $(2.4 \%)$ & $(1.2 \%)$ & $(2.4 \%)$ \\
Lactose & 70.8 & 63.6 & 70.8 & 63.6 & 70.8 & 63.6 & 70.8 & 63.6 \\
\hline
\end{tabular}

All quantities are expressed in milligrams

\section{4) EVALUATION OF CORE TABLETS}

\subsection{Precompressional studies}

\subsubsection{Flow Properties of Granules}

\subsubsection{Apparent Bulk density: ${ }^{17}$}

Apparent bulk density was determined by placing presieved granules into a graduated cylinder and measuring the volume and weight as it is. It was calculated by using formula

\section{Bulk density $=$ Mass $/$ volume}

\subsubsection{Tapped density: ${ }^{17}$}

Weighed sample of granules was transferred to a graduated cylinder and was tapped for a fixed number of taps (100). Tapped density was calculated by formula given in equation

\section{Tapped Density $=$ Weight of granules $/$ Tapped volume}

\subsubsection{Hausner's Ratio: ${ }^{18}$}

The Hausner's ratio is a number that is correlated to the flowability of a powder or granular material. It is calculated by formula given in equation

\section{Hausner's Ratio = Tapped Density / Bulk Density}

\subsubsection{Compressibility Index: ${ }^{18}$}

It is a simple test to evaluate bulk density and tapped density of granules and the rate at which it is packed down. The formula for Carr's index was given in equation

\section{Carr's Index $(\%)=[($ Tapped density-Bulk Density) x100]/Tapped Density}

\subsubsection{Angle of Repose: ${ }^{19}$}

The angle of repose of blend was determined by the fixed funnel method. The accurately weighed granules were taken in the funnel. The height of the funnel was adjusted in such a way that the tip of the funnel just touched the apex of the blend. The blend was allowed to flow through the funnel freely onto the surface. The diameter of the powder cone was measured and angle of repose was calculated using the formula given in equation
$\operatorname{Tan} \theta=\mathbf{h} / \mathbf{r}$

Where, $\mathrm{h}$ and $\mathrm{r}$ are the height and radius of the powder cone

\subsection{Post Compressional Studies}

\subsubsection{Shape and Appearance: ${ }^{20}$}

Tablets were examined under a lens for the shape of the tablet, and colour was observed by keeping the tablets in light.

\subsubsection{Hardness: ${ }^{21}$}

Monsanto hardness tester was used for the determination of the hardness. The tablet to be tested was held between a fixed and a moving jaw and reading of the indicator was adjusted to zero. The force applied to the edge of the tablet was gradually increased by moving the screw knob forward .until the tablet broke. The reading was noted from the scale which indicates the pressure required in $\mathrm{kg}$ or $\mathrm{lb}$ to break tablets.

\subsubsection{Thickness: ${ }^{20}$}

The crown-to-crown thickness of ten tablets from each batch was determined using vernier caliper. The thickness variation limits allowed are $\pm 5 \%$ of the size of the tablet.

\subsubsection{Weight Variation: ${ }^{20}$}

Weight variation study was carried out as per USP. Twenty tablets were randomly selected from each batch weighed individually. The average weight and standard deviation was calculated.

\subsubsection{Friability: $:^{22,23}$}

Roche friabilator (Electrolab Mumbai) was used for testing the friability of prepared tablets. Twenty tablets were weighed accurately and placed in the friabilator and rotated at $25 \mathrm{rpm}$ for a period of $4 \mathrm{~min}$. Tablets were dedusted using soft muslin cloth and weighed again. Percentage weight loss was determined by using following formula.

$\%$ Friability $=\quad[($ Initial weight- Final weight $) /$ Initial weight] X 100 


\subsubsection{Uniformity of Drug Content: ${ }^{24}$}

For determination of drug content, five tablets from each formulation were triturated using mortar and pestle. An accurately weighed powder equivalent to $400 \mathrm{mg}$ of drug was taken in $100 \mathrm{ml}$ volumetric flask and diluted with

\section{5) PREPARATION OF COATING SOLUTION}

sufficient amount of phosphate buffer of $\mathrm{pH} 6.8$ up to mark. Then the sample was sonicated for $1 \mathrm{hr}$ and filtered. An aliquot of the filtrate was diluted suitably and analyzed spectrophotometrically at $331.60 \mathrm{~nm}$ against blank. The test was done in triplicate and average drug content was estimated.

Table 3: Trials of Coating Using Combination of Eudragit S-100 and L-100

\begin{tabular}{ccccc}
\hline Ingredient & Function & F4 & F5 & F6 \\
\hline Eudragit S-100 & Enteric Polymer & 16 & 16 & 16 \\
Eudragit L-100 & Enteric Polymer & 16 & 16 & 16 \\
Diethyl phthalate & Plasticizer & 4 & 4 & 4 \\
Acetone & Solvent & 250 & 250 & 250 \\
IPA & Solvent & 250 & 250 & 250 \\
\% coating & & $*$ Quantity in grams & $10 \%$ & $12 \%$ \\
\hline
\end{tabular}

\section{Parameter Value}

Inlet Air Temperature $=40-45^{\circ} \mathrm{C}$

Exhaust Temperature $=30-35^{\circ} \mathrm{C}$

Bed Temperature $=38^{\circ} \mathrm{C}$

Atomization $($ bar $)=2$

Spray rate $(\mathrm{gm} / \mathrm{min})=10$

Pan RPM = 10

\section{6) EVALUATION OF ENTERIC COATED TABLETS}

\subsection{Hardness Test: ${ }^{21}$}

The hardness of the coated tablets was measured using same procedure as described earlier with the help of Monsanto hardness tester. The hardness of various formulations was shown in table 9.

\subsection{Weight Variation Test: ${ }^{20}$}

The weight variation test was carried out for the coated tablets using the same procedure as described earlier and the results were reported in the table 9.

\subsection{In-vitro Disintegration Test of Coated Tablets: ${ }^{22}$}

Tablet disintegration was carried by placing one tablet in each tube of the basket and top portion of the each tube was closed with disc. Tablets were firstly tested in $0.1 \mathrm{~N}$ $\mathrm{HCl}$ for $2 \mathrm{~h}$ (simulated gastric transit time) to see the damage to the coat. Afterwards, tablets were tested in the phosphate buffer $\mathrm{pH} 6.8$ (simulated colonic $\mathrm{pH}$ ) till the coating dissolved. Temperature in each case was kept at $37 \pm 0.5^{\circ} \mathrm{C}$. Disintegration time was reported in min. The time taken for complete disintegration of the tablet with no palpable mass remaining in the apparatus was measured. The experiment was carried out in triplicate.

\subsection{Lag Time Profile: ${ }^{25}$}

Time dependent systems are formulated to undergo a lag time of predetermined span of time of no release, followed by a rapid and complete release of loaded drug. Lag time is the time required to transit from the mouth to the colon.

\subsection{In-vitro Dissolution Profile of Mesalazine Coated} Tablets:
In vitro drug release studies for the prepared tablets were conducted for a period of 12 hours using USP type-II (Paddle) dissolution apparatus (Electro lab, Mumbai.) at $37 \pm 0.5^{\circ} \mathrm{C}$ and $75 \mathrm{rpm}$ speed using $\mathrm{pH} 1.2$ buffer for initial $2 \mathrm{~h}$, phosphate buffer of $\mathrm{pH} 7.4$ up to $3 \mathrm{~h}$ as and phosphate buffer of $\mathrm{pH} 6.8$ for $7 \mathrm{~h}$ as dissolution medium. At predetermined interval of time, $10 \mathrm{ml}$ of sample was withdrawn from the dissolution medium and replaced with fresh medium to maintain the volume constant. After filtration and appropriate dilution, the sample solutions were analyzed at $302 \mathrm{~nm}$ (acidic media) and 331.70nm (basic media) for Mesalazine by a UV-visible spectrophotometer. The amount of drug present in the samples was calculated and the results were reported in tables 10 (a) and 10(b).

\section{7) COMPARISON OF THE BEST FORMULATION WITH THE MARKETED FORMULATION}

The best formulation was selected on the basis of the release profile and lag time and compared with the marketed formulation (Asacol).

\section{8) SIMILARITY FACTOR ${ }^{26-28}$}

The similarity factor $\left(f_{2}\right)$ is a logarithmic transformation of the sum-squared error of differences between the test $T_{t}$ and reference products $\mathrm{R}_{\mathrm{t}}$ over all time points. It represents closeness of two comparative formulations. Generally similarity factor in the range of 50-100 is acceptable according to US FDA. Equation for calculation of similarity factor:

$$
\mathbf{f}_{2}=50 \times \log \left\{\left[1+(1 / n) \sum_{t=1} * \mathbf{n}\left(\mathbf{R}_{\mathbf{t}}-\mathbf{T}_{\mathbf{t}}\right)^{2}\right]^{-0.5} * 100\right\}
$$

$R_{t}$ and $T_{t}$ are the cumulative percentage dissolved at each of the selected $\mathrm{n}$ time points of the reference and test product respectively.

\section{9) STATISTICAL ANALYSIS}

The data was analyzed by using one way Analysis of Variance (ANOVA) followed by Tukey and Dunnett tests by using Graph pad prism software. The value of $\mathrm{p}<0.05$ was considered to be statistical significant.

\section{0) RELEASE KINETIC OF SELECTED FORMULATION ${ }^{29-31}$}

To examine the drug release kinetics and mechanism, the cumulative release data were fitted to models representing. 
- Zero order (cumulative \% drug release v/s. time).

- First order (log cumulative \% drug remaining v/s. time).

- Higuchi model (cumulative \% drug release v/s. Square root of time).

- Korsemeyer Peppas model (log cumulative \% drug release v/s. $\log$ time).

\section{1) STABILITY STUDY}

The selected batch (F2) was kept at $40^{\circ} \mathrm{C}$ with $75 \% \mathrm{RH}$ and the samples were withdrawn at 30,60 and 90 days for physical and in-vitro evaluation of drug release.

Table 4: Stability Study

\begin{tabular}{|c|c|c|c|c|}
\hline Parameter & Initial & $\begin{array}{c}1 \text { month } \\
\left(40^{\circ} \mathrm{C} / 75 \% \mathrm{RH}\right)\end{array}$ & $\begin{array}{c}2 \text { month } \\
\left(40^{\circ} \mathrm{C} / 75 \% \mathrm{RH}\right)\end{array}$ & $\begin{array}{c}3 \text { month } \\
\left(40^{\circ} \mathrm{C} / 75 \% \mathrm{RH}\right)\end{array}$ \\
\hline Description & $\begin{array}{l}\text { Yellowish brown, } \\
\text { round shaped }\end{array}$ & Same & Same & Same \\
\hline Average weight (mg) & 681.10 & 681.10 & 681.10 & 681.10 \\
\hline Hardness $\left(\mathrm{kg} / \mathrm{cm}^{2}\right)$ & 6.61 & 6.61 & 6.61 & 6.61 \\
\hline & & Dissolution Study & & \\
\hline $\mathbf{0}$ & 0 & 0 & 0 & 0 \\
\hline 1 & 0 & 0 & 0 & 0 \\
\hline 2 & 0 & 0 & 0 & 0 \\
\hline 3 & 0 & 0 & 0 & 0 \\
\hline 4 & 8.52 & 7.99 & 7.85 & 6.90 \\
\hline 5 & 18.45 & 17.85 & 16.72 & 16.49 \\
\hline 6 & 40.56 & 39.71 & 38.89 & 35.66 \\
\hline 7 & 50.42 & 52.02 & 52.11 & 47.02 \\
\hline 8 & 61.05 & 60.28 & 60.25 & 59.77 \\
\hline 9 & 69.58 & 68.66 & 67.41 & 68.98 \\
\hline 10 & 79.23 & 78.59 & 77.90 & 78.86 \\
\hline 11 & 89.42 & 89.42 & 89.45 & 89.31 \\
\hline 12 & 96.53 & 95.49 & 95.46 & 95.90 \\
\hline
\end{tabular}

6) RESULTS AND DISCUSSION

\subsection{ANALYTICAL METHOD VALIDATION}

Table 5: Characteristics and Validation Parameters of Mesalazine

\begin{tabular}{cccc}
\hline Validation Parameter & & Values & \\
\hline & In 0.1N HCl & In PB pH 6.8 & In PB pH 7.4 \\
$\lambda_{\max }(\mathbf{n m})$ & 302 & 331.60 & 331.70 \\
Linearity equation & $\mathrm{Y}=0.046 \mathrm{x}+0.021$ & $\mathrm{Y}=0.086 \mathrm{x}+0.038$ & $\mathrm{Y}=0.085 \mathrm{x}+0.018$ \\
Range $(\boldsymbol{\mu g} / \mathbf{m l})$ & $1-10$ & $1-10$ & $1-10$ \\
Intercept $(\mathbf{c})$ & 0.021 & 0.038 & 0.018 \\
$\mathbf{R}^{2}$ value & 0.993 & 0.995 & 0.996 \\
LOD $(\boldsymbol{\mu g} / \mathbf{m l})$ & 0.220 & 0.216 & 0.218 \\
LOQ $(\boldsymbol{\mu g} / \mathbf{m l})$ & 0.685 & 0.673 & 0.688 \\
\hline
\end{tabular}

The low values of $L O D$ and $L O Q$ indicated that the method was sensitive and validated.

\subsection{EVALUATION OF CORE TABLETS}

\subsubsection{Precompressional Studies}

6.2.1.1. Flow Properties of Granules

Table 6: Micromeritic properties of granules

\begin{tabular}{cccccc}
\hline $\begin{array}{c}\text { Formulation } \\
\text { code }\end{array}$ & $\begin{array}{c}\text { Bulk density } \\
(\mathbf{g m} / \mathbf{m l})\end{array}$ & $\begin{array}{c}\text { Tapped } \\
\text { density }(\mathbf{g} / \mathbf{m l})\end{array}$ & Carr's index (\%) & Hausner's ratio & $\begin{array}{c}\text { Angle of repose } \\
(\boldsymbol{\theta})\end{array}$ \\
\hline F1 & 0.366 & 0.497 & 26.35 & 1.355 & 38.2 \\
F2 & 0.364 & 0.494 & 26.31 & 1.357 & 37.5 \\
F3 & 0.361 & 0.490 & 26.33 & 1.357 & 38.6 \\
F4 & 0.367 & 0.499 & 26.45 & 1.359 & 35.0 \\
F5 & 0.362 & 0.494 & 26.72 & 1.364 & 32.9 \\
F6 & 0.367 & 0.491 & 25.25 & 1.337 & 33.4 \\
F7 & 0.365 & 0.496 & 26.41 & 1.358 & 34.6 \\
F8 & 0.366 & 0.492 & 25.60 & 1.344 & 37.4 \\
\hline
\end{tabular}

*All values are expressed as mean $\pm S D . n=3$. 
From the results of carr's index and hausner's ratio, it was concluded that except formulations F6 and F8, all the formulations possess poor flowability of granules. Formulations F6 and F8 were having passable flow of granules. From the results of angle of repose, it was concluded that except granules of F5 and F6, all other formulations possess poor flow. F5 and F6 were having passable flow.

\subsubsection{Physicochemical Evaluation of Core Tablets}

6.2. Post Compressional Studies:

\subsubsection{Shape and Appearance}

Tablets showed standard concave surfaces with circular shape. Tablets were light brownish in color.

Table 7: Physicochemical Evaluation of Core Tablets of Mesalazine

\begin{tabular}{|c|c|c|c|c|c|}
\hline $\begin{array}{c}\text { Formulation } \\
\text { Code }\end{array}$ & Thickness ${ }^{*}(\mathrm{~mm})$ & $\begin{array}{c}\text { Weight }^{* * *} \\
\text { (uncoated } \\
\text { tablets) } \\
\text { (mg) }\end{array}$ & $\begin{array}{c}\text { Hardness } \\
\text { (uncoated } \\
\text { tablets) } \\
\left(\mathrm{kg} / \mathrm{cm}^{2}\right)\end{array}$ & $\begin{array}{c}\text { Content } \\
\text { uniformity }^{*}(\%)\end{array}$ & Friability $^{* *}(\%)$ \\
\hline F1 & $5.41 \pm 0.771$ & $600.20 \pm 1.64$ & $5.8 \pm 0.37$ & $99.97 \pm 0.556$ & 0.17 \\
\hline F2 & $5.30 \pm 0.771$ & $600.25 \pm 1.48$ & $5.74 \pm 0.15$ & $100.15 \pm 0.56$ & 0.15 \\
\hline F3 & $5.10 \pm 0.773$ & $600.15 \pm 1.56$ & $6.08 \pm 0.13$ & $100.18 \pm 0.74$ & 0.20 \\
\hline F4 & $5.00 \pm 0.771$ & $600.10 \pm 1.29$ & $6.1 \pm 0.29$ & $99.02 \pm 0.950$ & 0.21 \\
\hline F5 & $5.12 \pm 0.774$ & $600.05 \pm 1.3$ & $6.36 \pm 0.15$ & $101.04 \pm 0.68$ & 0.12 \\
\hline F6 & $5.16 \pm 0.772$ & $599.05 \pm 1.19$ & $6.62 \pm 0.11$ & $99.57 \pm 0.31$ & 0.14 \\
\hline F7 & $5.24 \pm 0.772$ & $600.25 \pm 1.4$ & $6.27 \pm 0.24$ & $95.25 \pm 0.25$ & 0.17 \\
\hline F8 & $5.10 \pm 0.771$ & $600.10 \pm 1.29$ & $6.23 \pm 0.19$ & $96.75 \pm 0.95$ & 0.16 \\
\hline
\end{tabular}

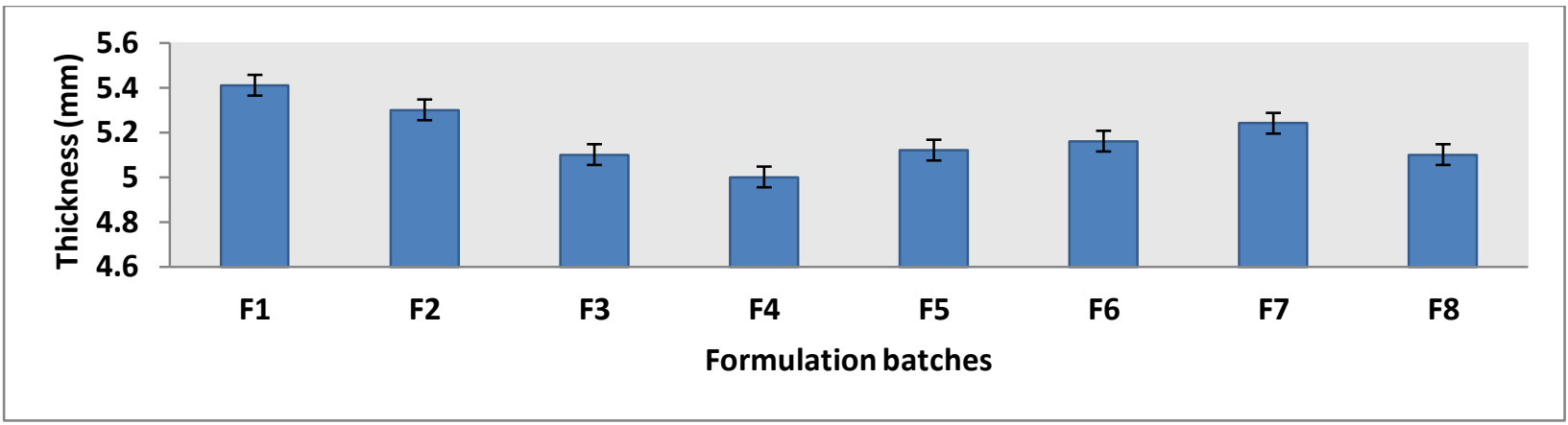

Graph 1: Thickness of the Formulation Batches (F1-F8)

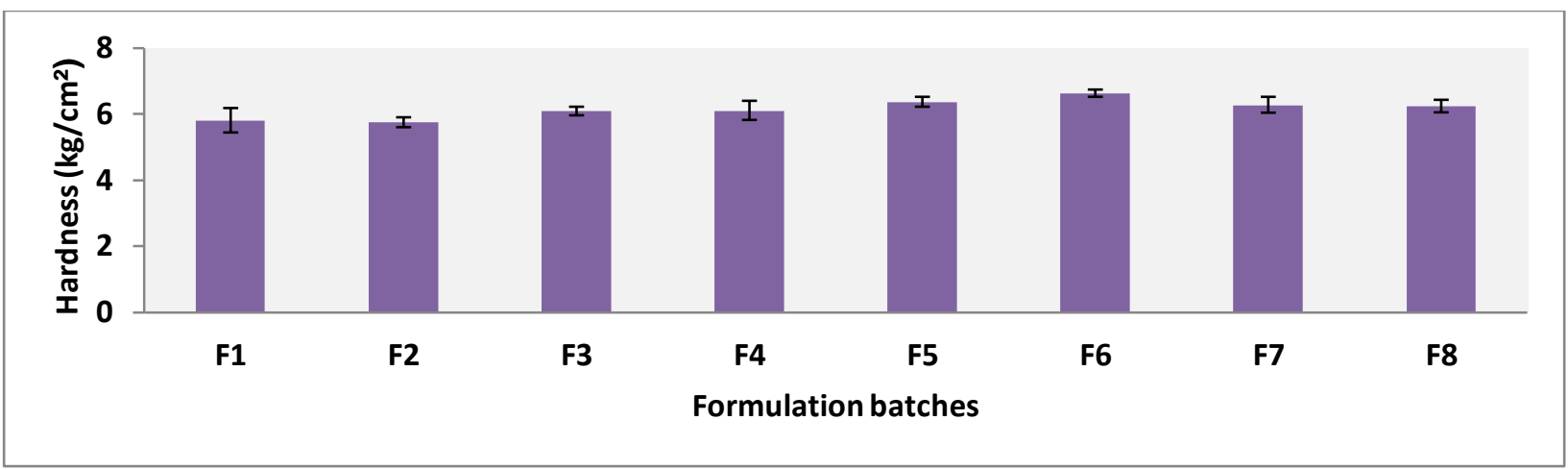

Graph 2: Hardness of the Formulation Batches (F1-F8)

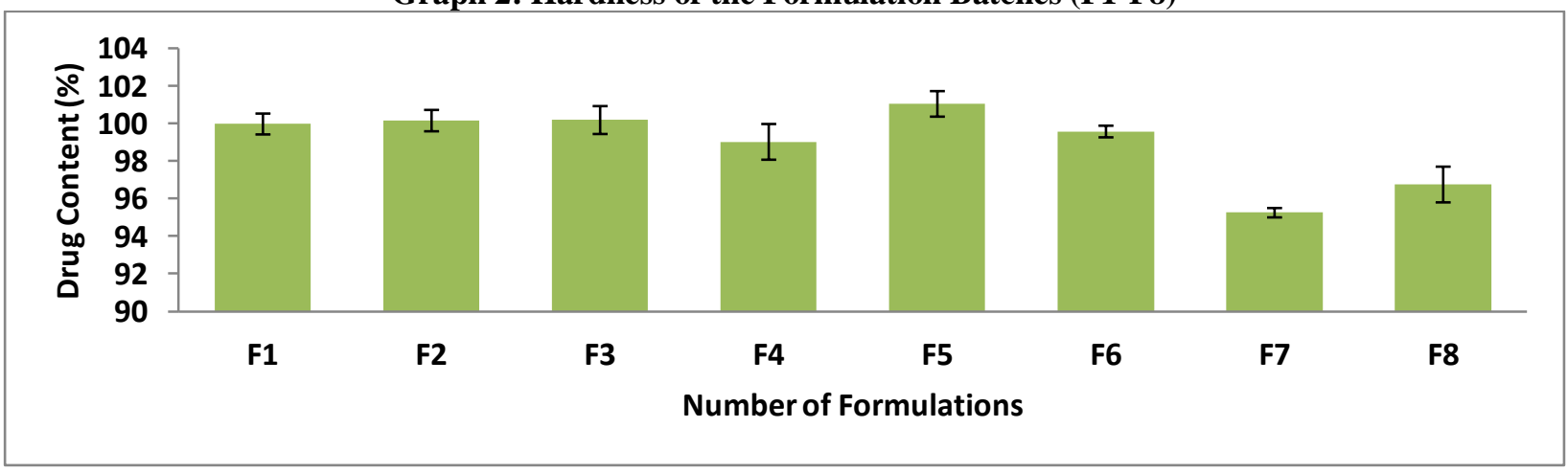

Graph 3: Percent Drug Content of the Formulation Batches (F1-F8) 


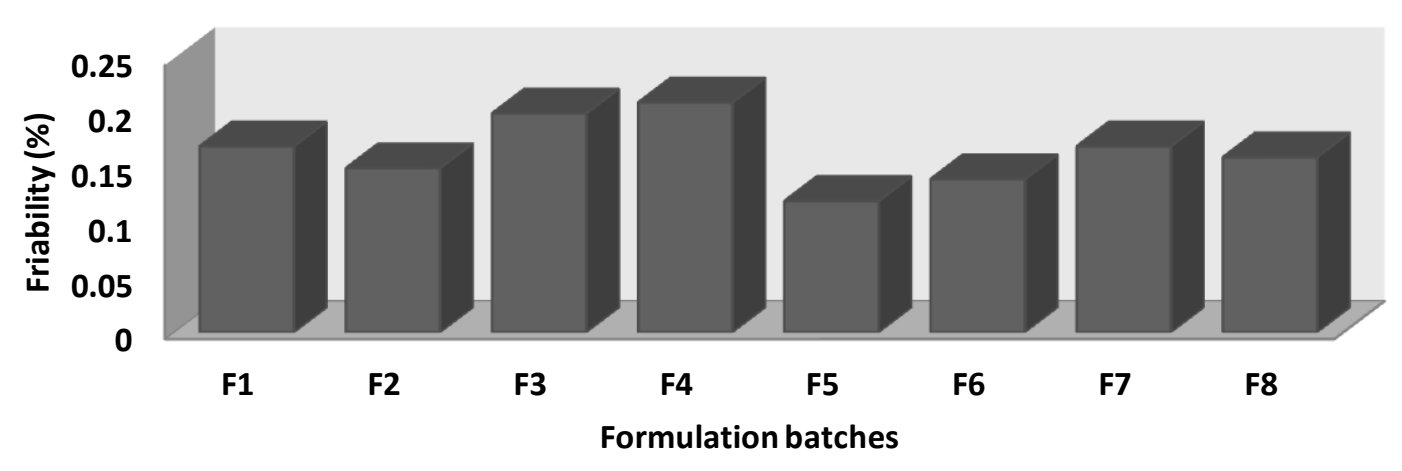

\section{Graph 4: Friability of the Formulation Batches (F1-F8)}

6.3. TRIALS OF COATING WITH COMBINATION OF EUDRAGIT L-100 AND EUDRAGIT S-100 IN COMBINATION:

The cumulative in-vitro release study was carried out using USP dissolution apparatus type II. Cumulative \% drug release after $7 \mathrm{hrs}$ was found to be $45.28 \%, 50.11 \%$ and $38.17 \%$ for formulation F4, F5 and F6 respectively. The release before completion of lag time was found to be $16.25 \%, 19.33 \%$ and $12.14 \%$ for formulation F1, F2 and $\mathrm{F} 3$ respectively.
The results obtained in the in-vitro drug release study are tabulated in Table 8. The cumulative percentage of Mesalazine released as a function of time for all the formulations are shown in graph 5. Coating of tablets with Eudragit L-100: Eudragit S-100 in combination showed the lag time of nearly 5 hrs before burst effect. From the result, concluded that the combination of Eudragit L-100: Eudragit S-100 can be successfully utilized to create desired release profile similar to the targeted release profile in future study.

Table 8: In-vitro Release Profile During Trials of Coating With Eudragit S-100 and L- 100 in Combination:

\begin{tabular}{ccccc}
\hline $\begin{array}{c}\text { Dissolution } \\
\text { media }\end{array}$ & $\begin{array}{c}\text { Time } \\
\text { (hours) }\end{array}$ & \multicolumn{3}{c}{ Cumulative \% drug release } \\
\hline & & $\mathbf{F 4}$ & $\mathbf{F 5}$ & $\mathbf{F 6}$ \\
$\mathbf{0 . 1}$ N HCl & 0 & 0 & 0 & 0 \\
& 1 & 0 & 0 & 0 \\
PB pH 7.4 & 2 & 0 & 0 & 0 \\
& 3 & 0 & 7.19 & 6.13 \\
& 4 & 7.36 & 15.33 & 12.14 \\
& 5 & 16.25 & 42.19 & 26.09 \\
PB pH 6.8 & 7 & 35.23 & 50.11 & 48.17 \\
& 8 & 45.28 & 61.14 & 56.82 \\
& 9 & 57.54 & 70.72 & 67.59 \\
& 10 & 66.35 & 75.4 & 75.32 \\
\hline
\end{tabular}

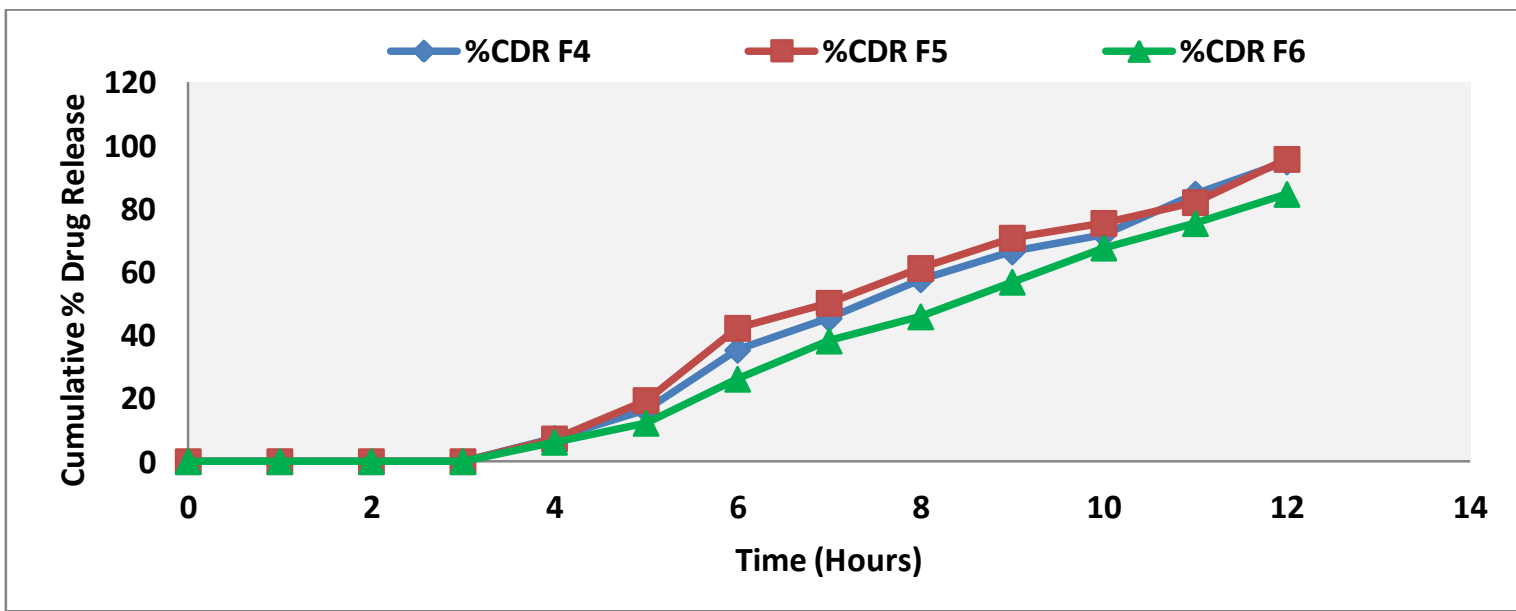

Graph 5: In-vitro Release Profile of Formulations (F4-F6) During Trials of Coating with Eudragit S- 100 and L- 100 in Combination 
Table 10(b): In-vitro Drug Release Study of Mesalazine Coated Tablets (F5-F8)

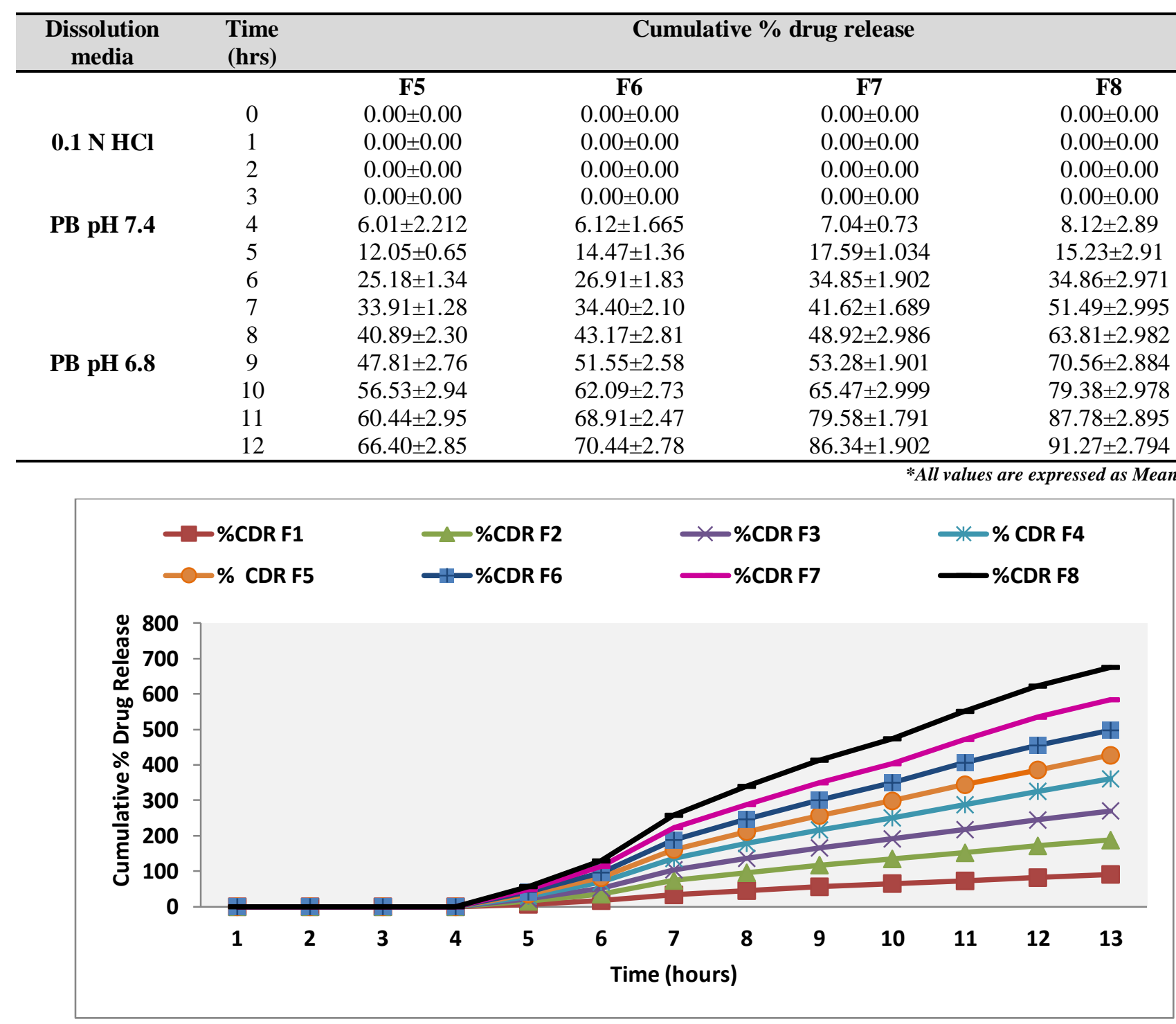

\section{Graph 7: Effect of Polymer Level on In-vitro Release of Mesalazine From Enteric Coated Tablets (F1-F8)}

The results obtained were in agreement with the fact that formulations having higher percentage of HPMC K15M as a matrix former show much more retardation of drug release as compared to the formulations having lower percentage of HPMC K15M. Formulation F5 and F6 show least amount of drug release in dissolution study illuminating the effect of HPMC K15M concentration in the formulations.

Reason: Presence of HPMC K15M forms a much more viscous layer around the tablet allowing less seepage of fluid into the tablet to prolong the drug release. Higher concentration of HPMC K15M provides gel layer which was more viscous as compared to that formed by lower concentration of HPMC K15M.

Instead of higher concentration of HPMC K15M in the formulations F5 and F6, drug release values were almost nearer to the release values obtained from formulations F3 and F4 which were having lower concentration of HPMC K15M.

Reason: This was due to the higher molecular weight of the polymer. Owing to higher molecular weight, polymer chains were also bulkier in nature requiring more time for their unwinding by solvent molecules leading to delay in instant swelling of the polymer. This delay was responsible for the higher drug release from the formulations having higher concentration of HPMC K15M.

Effect of Polymer Type and Concentration on Drug Release Behaviour:

From the results of in vitro dissolution studies, it was clear that drug release depends upon the type of polymer and concentration of polymer. Drug release was found to be higher in case of formulations based on HPMC K4M.

Reason: Being more viscous in nature, HPMC K-15M reduces the seepage of dissolution media into tablet core, hence sustain the release of drug. Delay in drug release was also owing to the enormous swelling potential of HPMC K15M which led to increase in diffusion path length. Dissolution results in pH 6.8 medium were also in correlation with above explanation.

Effect of Superdisintegrant Concentration on Drug Release Behaviour: 
Formulations having higher concentration of crosspovidone showed greater drug release as compared to that having lower concentration in the matrix of tablets. This was also clear from the comparison between dissolution results of formulations F1 and F2, F3 and F4, F5 and F6 followed by F7, F8 in dissolution medium of $\mathrm{pH}$ 6.8 .

Reason: Increased drug release in formulations containing higher amount of superdisintegrant was due to the formation of pores and cavities in the matrix of tablets. Seepage of the dissolution medium in the matrix of tablets allows rapid swelling of tablet to provide burst effect. Swelling of the tablet depends upon the concentration of superdisintegrant in the formulation; higher amount of superdisintegrant provides higher swelling. But presence of rate controlling hydrophilic polymers do not allows drug to be released at rapid rate and sustained the release of drug. Due to this reason the drug release of formulations F2, F4, F6 and F8 is more than F1, F3, F5 and F7.

\subsection{COMPARISON OF THE OPTIMIZED FORMULATION WITH THE MARKETED FORMULATION}

From the in-vitro dissolution studies shown in table 10 (a) and 10(b), it was obvious that formulation F2 achieved more than $95 \%$ of the drug release in the time period and it had the lag time of 3.5 hours. So, it was best fitted to be called as optimized formulation. While the release of the marketed formulation was upto $63.449 \%$ in the small intestine this is because of the enteric coating using Eudragit S-100 alone. So there was a premature release of drug in small intestine.

Moreover, $100 \%$ release of the drug was shown by the marketed formulation in 8 hours. While the formulation F2, being the sustained release formulation released the drug upto 12 hours.

The in-vitro release profiles of both the optimized formulation, F2 and the marketed formulation, M1 are plotted in graph 8 .

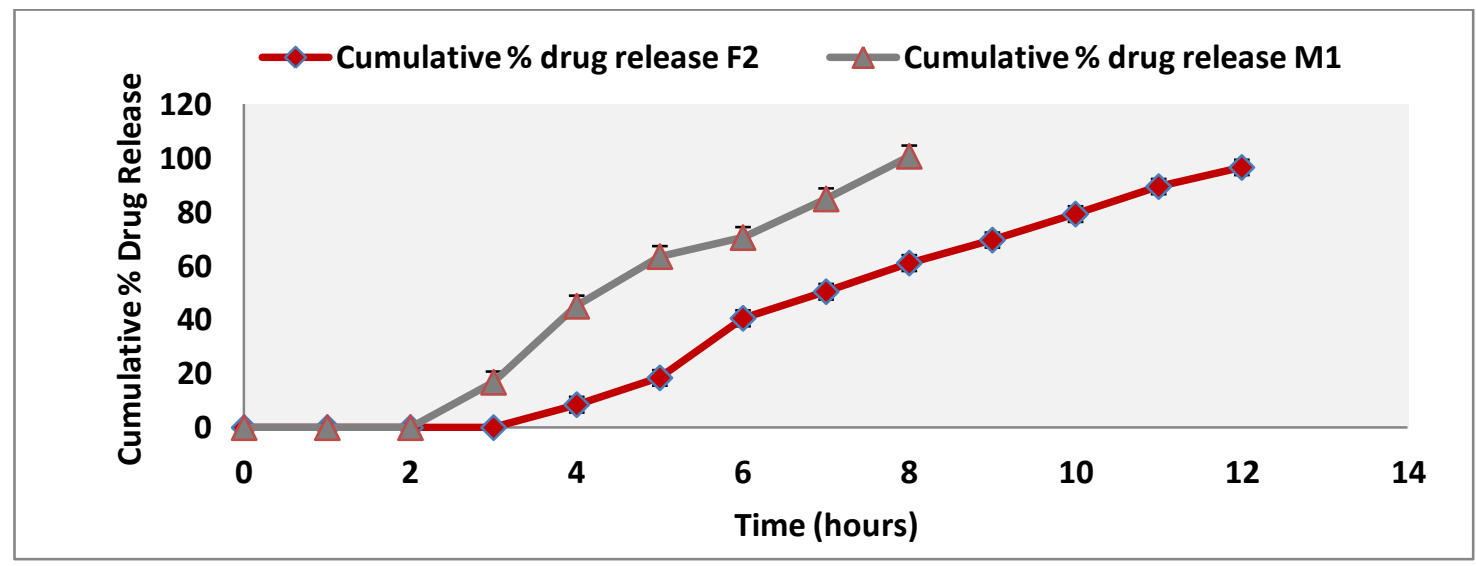

Graph 8: Comparison of the Marketed Formulation (M1) and the Best Formulation (F2)

\subsection{SIMILARITY FACTOR}

The result of similarity factor is 20.125 . Because the value of similarity factor is less than 50 so, it was concluded that there was a significant difference between dissolution profiles of optimized formulation and the marketed formulation. Because the dissolution profiles are considered to be similar when similarity factor (f2) is between 50 and 100 .

\subsection{STATISTICAL EVALUATION}

From ANOVA all the results were expressed as Mean \pm Standard Error. The data was analyzed by using one way Analysis of Variance (ANOVA) followed by Tukey and Dunnett tests by using Graph pad prism software. The value of $p<0.05$ was obtained and we conclude that all the values were statistically significant.

Table 11: Calculation of ANOVA: Single Factor

\begin{tabular}{cccccccc}
\hline Batch & $\begin{array}{c}\text { Analysis of } \\
\text { variance }\end{array}$ & SS & df & MS & F & P-value & F $_{\text {crit }}$ \\
\hline F1 & Between groups & 5937.928 & 1 & 5937.928 & 9.830951 & 0.004489 & 4.259677 \\
F2 & Between groups & 7303.338 & 1 & 7303.338 & 10.53471 & 0.003438 & 4.259677 \\
F3 & Between groups & 4485.734 & 1 & 4485.734 & 9.399612 & 0.005304 & 4.259677 \\
F4 & Between groups & 5328.472 & 1 & 5328.472 & 9.543051 & 0.005016 & 4.259677 \\
F5 & Between groups & 2825.071 & 1 & 2825.071 & 8.507464 & 0.007556 & 4.259677 \\
F6 & Between groups & 3462.923 & 1 & 3462.923 & 8.184894 & 0.006679 & 4.259677 \\
F7 & Between groups & 4893.375 & 1 & 4893.375 & 4.58037 & 0.004944 & 4.259677 \\
F8 & Between groups & 6930.779 & 1 & 6930.779 & 10.19862 & 0.003901 & 4.259677 \\
\hline
\end{tabular}




\subsection{KINETICS OF DRUG RELEASE}

The value of release exponent (n) was found to be a function of polymer used and the physicochemical property of a drug molecule itself. Kinetic results revealed that, all the formulations followed zero order kinetics as correlation coefficient $\left(\mathrm{r}^{2}\right)$ values (0.919-0.953) are higher than that of first order release kinetics. The prepared tablets showed supercase-II transport release, as the values of release exponent (n) lies between 2.076-2.213 with correlation coefficient $\left(\mathrm{r}^{2}\right)$ values upto 0.952 , indicating that erosion of polymeric chain was involved in the release process. $^{31}$

Table 12: Regression Analysis $\left(\mathbf{R}^{2}\right)$ of Release Data Based on Best Curve-Fitting Method for Different Formulations of Mesalazine Tablets $(n=3)$

\begin{tabular}{ccccccccc}
\hline Formulation & \multicolumn{2}{c}{ Zero order } & \multicolumn{2}{c}{ First Order } & \multicolumn{2}{c}{ Higuchi } & \multicolumn{2}{c}{ Korsemeyer Peppas } \\
\cline { 2 - 8 } & $\mathbf{n}$ & $\mathbf{R}^{2}$ & $\mathbf{n}$ & $\mathbf{R}^{2}$ & $\mathbf{n}$ & $\mathbf{R}^{2}$ & $\mathbf{n}$ & $\mathbf{R}^{2}$ \\
F1 & 8.646 & 0.950 & -0.080 & 0.851 & 30.29 & 0.781 & 2.213 & 0.924 \\
F2 & 9.280 & 0.952 & -0.103 & 0.803 & 32.64 & 0.789 & 2.092 & 0.920 \\
F3 & 7.684 & 0.953 & -0.060 & 0.886 & 26.92 & 0.784 & 2.138 & 0.93 \\
F4 & 8.318 & 0.952 & -0.074 & 0.833 & 29.05 & 0.778 & 2.091 & 0.952 \\
F5 & 6.379 & 0.951 & -0.042 & 0.925 & 22.37 & 0.783 & 2.122 & 0.938 \\
F6 & 6.946 & 0.949 & -0.048 & 0.911 & 24.32 & 0.780 & 2.137 & 0.940 \\
F7 & 7.942 & 0.950 & -0.066 & 0.850 & 27.81 & 0.781 & 2.076 & 0.923 \\
F8 & 9.139 & 0.942 & -0.089 & 0.880 & 32.13 & 0.780 & 2.198 & 0.920 \\
\hline
\end{tabular}

\subsection{STABILITY STUDY}

The selected formulation (F2) was found to be stable upon storage for 3 months. No change was observed in the appearance, hardness and average weight of the tablet. Also no significant change was observed in the in-vitro release of the drug.

\section{CONCLUSION}

From the above results we can conclude that Mesalazine formulations prepared with HPMC K4M, HPMC K 15M and crosspovidone showed acceptable properties like friability, weight variation, hardness etc and in-vitro drug release which remained unchanged upon storage for 3 months. However, HPMC K4M, HPMC K15M and

\section{REFERENCES}

1) Anthony CM, David OM, Widdop B. Clarke's Analysis of Drugs and Poisons. $3^{\text {rd }}$ edition. Pharmaceutical press; 2005.

2) Patel TD, Patel DM, Patel CN, Parikh BN, Gothi GD, Formulation and development of enteric coated $\mathrm{pH}$ dependent compression coated tablets of mesalamine, J Global Pharm Tech, 2010, 2(6), 118-124.

3) Patel M, Shah T, Amin A, Therapeutic opportunities in colon specific drug delivery system, Crit Rev Ther Drug Carrier Syst, 2007, 24, 147-202.

4) Lee VHL. Changing needs in drug delivery in the era of peptide and protein drugs. In: Lee VHL. (Eds.). Peptide and protein drug delivery. Marcel Dekker Inc., New York, pp. 156.

5) Patel MM, Shah TJ, Amin AF, Design, development and optimization of a novel time and $\mathrm{pH}$ dependent colon targeted drug delivery system, Pharmaceut Develop Tech, 2009, 14(1), 65-72.

6) Gohel MC, Parikh RK, Parikh SA, Nagori, MR, Design of a potential colonic drug delivery system of mesalamine, Pharmaceut Develop Tech, 2008, 13(5), 447-456.

7) Watts PJ, Illum L, Colonic drug delivery, Drug Dev Ind Pharm, 1997, 23, 893-913.

8) Sinha VR, Kumria R, Polysaccharides in colon-specific drug delivery, Int J Pharm, 2001, 224, 19-38. crosspovidone $(2.4 \%)$ based Mesalazine tablets with the formulation code F2 proved to be the formula of choice, since it showed the highest drug release and lag time when compared to the marketed formulation, Asacol. So, Mesalazine tablets can be used in sustained delayed drug delivery in treatment of ulcerative colitis so as to reduce the side effects of drug in stomach and also to reduce the dosing frequency of the drug.

\section{ACKNOWLEDGEMENT}

Authors are thankful to Colorcon Asia private limited, Goa for providing free gift sample of HPMC K4M and HPMC K15M. Also thankful to Akal College of Pharmacy, Mastuana Sahib and Rayat Institute of Pharmacy, Ropar for work in the research article.
9) Qi ML, Wu DZ, Design and in-vivo evaluation of colonic drug delivery systems, Chinese J Clin Pharm, 2000, 16, 150154.

10) United States Pharmacopoiea, The official compendia of standards, Asian Edition, 2005; USP 28 NF23: 1087.

11) Kun NA, You HB, pH sensitive polymers for drug delivery. In: Glen S.K. (Eds), Polymer drug delivery systems. Taylor and Francis Group. FL, pp 129-194.

12) Khan MZI, Helena PST, Nevenka K, A pH dependent colon targeted oral drug delivery system using methacrylic acid copolymers.II. Manipulation of drug release using Eudragit L100 and Eudragit S 100 combinations. Drug Dev Ind Pharm, 26, 549-554.

13) Khan MZI, Prebeg Z, Kurjakovic N, A pH dependent colon targeted oral drug delivery system using methacrylic acid copolymers: I, Manipulation of drug release using Eudragit L100-55 and Eudragit S 100 combinations, J Control Rel, 58, 215-222.

14) Nugent SG, Kumar D, Rampton DS, Evans D, Intestinal luminal $\mathrm{pH}$ in inflammatory bowel disease: Possible determinants and implications for therapy with aminosalicylates and other drugs, Gut, 2001, 48, 571-577.

15) Sloka SN, Gurupadayya BM, Kumar CHA, Sensitive spectrophotometric method for the action of mesalamine in bulk and pharmaceutical formulations, Scholars research library, 2010, 2(4), 389-396. 
16) Validation of analytical procedures: Text and methodology. European Medicines Agency 1995.

17) http://www.aapspharmscitech.org. Reddy KR., Mutalik S, Reddy, S, Once daily sustained release matrix tablets of nicorandil: Formulation and in-vitro evaluation. AAPS Pharm Sci Tech, 2003, 4(4) article 61.

18) Aulton ME. Pharmaceutics, the science of dosage form design. $2^{\text {nd }}$ edition. London: ELBS/ Churchill Livingstone; 2002. 207-208.

19) Lieberman HA, Lachman L, Schwartz JB, Pharmaceutical dosage forms: Tablets. Vol 2. New York, Marcel Dekker; 1990. 201-43.

20) Indian Pharmacopoeia 23, New Delhi: Controller or publication, Inc, 1996. Volume 2: 555-6.

21) Gupta AK. Introduction to pharmaceutics, $2^{\text {nd }}$ edition. Vol 1. New Delhi, CBS publication; 1991. 270.

22) Banker GS, Anderson NR, 1987. Tablets. In: Lachman, L., Lieberman, HA, Kanig, KL, (Eds), The theory and practice of industrial pharmacy. Varghese publishing house, 294.

23) United States Pharmacopoeia 23, The National Formulary 18. Asian edition. MD: United States Pharmacopoiel convention, Inc, 1995. 1790-2.

24) Ratnakumari T, Chetty CM, Reddy Dwarkasnadha, Ramyakrishna P, Formulation and evaluation of aceclofenac matrix tablets for colon drug delivery, J Global Trends Pharmaceut Sci, 2010, 1(1), 53-60.

25) Patel DB, Patel DM, Parikh BN, Prajapati ST, Patel CN, A review on time dependent systems for colonic delivery, J Global Pharma Tech, 2010, 2(1), 65-71.

26) Yuksel N, Kanik AE, Baykara $\mathrm{T}$, Comparison of in-vitro dissolution profiles by ANOVA based model dependent methods, Int J Pharm, 2000, 209, 57-67.

27) Costa P, Jose MSL, Modeling and comparison of dissolution profiles. Eur J Pharm Sci, 2001, 13, 123-133.

28) Ocana J, Frutos G, Sanchez OP, Using the similarity factor $f 2$ in practice: A critical revision and suggestions for its standard error estimation; chemometrics and intelligen laboratory systems, 2009, 99, 49-56.

29) Ritger PL, Peppas NA, A simple equation for description of solute release. II fickian and anomalous release from swellable devices, J Control Rel, 1987, 5, 37-42.

30) Costa P, Lobo JMS, Divisability of diltiazem matrix sustained relase tablets, Pharm Dev Tech, 2001, 6(3), 343-51.

31) Peppas NA, A model of dissolution controlled solute release from porous drug delivery polymeric systems, J Biomed Mater Res, 1983, 17, 1079-87. 